\title{
Papers
}

Explorations into Children's Literature

\section{Dead Funny? The Ideological Use of Humour and Comedy in Saci Lloyd's The Carbon Diaries 2015 and 2017}

\author{
Dr. Alyson Miller, Dr. Rebecca Hutton, Dr. Elizabeth Braithwaite - Deakin \\ University
}

\begin{abstract}
The threat of environmental devastation, and the speed with which humanity is damaging the planet, are widely viewed as serious concerns in the twenty-first century. Yet the gravity which accompanies interpretations of such issues can also serve as 'a fruitful starting point for humor' born of 'incongruence[s] between the serious and the non-serious' (Lyyktimäki 2015, p. 178). In Saci Lloyd's young adult novels The Carbon Diaries 2015 and The Carbon Diaries 2017, humour and comedy contribute to each text's attempts to encourage implied young adult readers to engage critically with the threat of ecological devastation, even though the questions of how to reduce the likelihood of ecological disaster most effectively on a broad scale, and how best to bring about responsible use of the environment, are problems which are still a long way from being answered.
\end{abstract}

Keywords: environment, irony, saci Lloyd, carbon diaries, young adult fiction, humour

\section{Introduction}

Ecological degradation and disaster are widely considered to be serious concerns, as attested by such global events as the 1992 United Nations Conference on Environment and Development, which aimed to place sustainability and ecological management clearly on the public agenda (see United Nations 2016), and the congresses on Climate Change and Global Warming, the third of which occurs in 2017 (Conference Series LLC (2013-2017)). Yet the gravity which accompanies interpretations of issues such as environmental conscience and sustainability can also serve as 'a fruitful starting point for humor' born of 'incongruence[s] between the serious and the non-serious' (Lyyktimäki 2015, p. 178). In Saci Lloyd's young 
adult novels The Carbon Diaries 2015 and The Carbon Diaries 2017, humour and comedy contribute to each text's attempts to encourage implied young adult readers to engage critically with the threat of ecological devastation, considered to be one of the twenty-first century's biggest challenges (see Chase-Dunn and Lawrence 2011). This paper argues that humour, comedy and parody intersect with, and become implicated in, the socialising agendas of Lloyd's novels. Irony-which 'include[s] at least two layers of meaning within [a given] phenomenon and some kind of incongruence between the layers' (Lyytimäki, p. 180) - is the predominant feature of how the humour operates in Lloyd's grave new world. However, comedy and parody also work together with irony within The Carbon Diaries books to create a subject position for the reader which is based in 'the recognition of the inevitability of failure and error' when it comes to the widespread and sustained ethical use of the natural environment, but which also understands 'the need to act, with due care, in the very face of that recognition' (Szerszynski 2007, p. 351). In other words, although it may be impossible to find a global solution to the threat of environmental devastation, it is important still to continue to ask the question of how the resources of the earth may best be used.

Both novels are set primarily in England in the early twenty-first century. In The Carbon Diaries 2015, carbon has been rationed in an attempt to prevent the levels of carbon dioxide in the atmosphere from reaching the point where irreparable climate change happens globally (Lloyd 2008, front matter) and citizens are allowed only a certain number of carbon points per year in order to run appliances, travel and for entertainment. If these points are used before the year is up 'you're all alone, sobbing in the dark' $(2008$, p. 8). Both the 2015 and 2017 volumes take the form of teenager Laura Brown's diary as she chronicles the first year of the country's carbon rationing (in the 2015 text), and then her experiences both at home and abroad as the climate situation worsens and government controls become harsher (the 2017 volume).

While the first of The Carbon Diaries texts is written in such a way as to provoke laughter, and the second has its moments of humour despite being darker in tone, the actual events 
described in the texts are often not ones which a reader might be expected to find funny, such as the significant reduction in the characters' standard of living outlined in the 2015 text, for example, or Laura and her friends being arrested and held in squalid conditions as in The Carbon Diaries 2017 (2009, pp. 285-292). Consideration of the means by which each text might endeavor to position the implied reader to find an utterance or situation funny is crucial to exploring how the texts function ideologically. Brett Mills $(2005$, p. 16) draws a distinction between humour and comedy by arguing that "humour is more of a general tone, pervading all parts of a text, and existing even when nothing specifically funny is taking place'. Comedy, by contrast, 'suggests material whose primary purpose is one of funniness' and which is structured to produce a particular response (p. 17). In other words, comedy has more to do with the technique of presentation, whereas humour can be spontaneous and accidental. But, as Jari Lyytimäki (2015, p. 178) points out, 'Not all humour is funny'. Dark humour, that which 'deals with topics that are considered as awkward, or even taboo in a deeply ironic manner' (p. 178), is a particular feature of the second of Lloyd's Carbon Diaries texts and a key tool in attempts to position the implied young adult reader to consider the implications of a world heading towards ecological devastation, and of the means by which that devastation may be averted.

The Carbon Diaries novels are premised upon political and environmental climates at odds with any sense of amusement or mirth. The incongruity between the comic and the tragic in these texts can both intensify and alleviate guilt for readers. The reason for this is that, on the one hand, comedy is corrective. In 1698 William Congreve wrote that:

[t]he business of comedy is to delight as well as to instruct; and as vicious people are made ashamed of their follies and faults by seeing them exposed in a ridiculous manner, so are good people at once both warned and diverted at their expense (1997, p. 515).

On the other hand, comedy can also function as relief or catharsis: that is, as a way to discharge psychological tension. As Dana F. Sutton argues, Aristotle's theory that tragic 
catharsis both 'purges the spectator' of the fear in the play, and also of the 'anxiety and fear' created by not only anxiety and fear themselves but also by other sources, could be usefully adapted to comedy (Sutton 1994, p. 41). In other words, the catharsis provided by comedy can also relieve a range of tensions within the viewer or reader, but it does so by evoking amusement and enjoyment (see Sutton, pp. 41-48).

By employing 'highly crafted' and corrective comedy alongside cathartic 'incidental' humour (D’Arcens 2014 p. 16), The Carbon Diaries texts create a perplexing pedagogical field for readers. The text constructs an intricate entwinement of shame and levity that both seeks to encourage cognitive and behavioural changes in readers while also offering opportunities for readers to disavow themselves of the anxieties of the disaster in which they are engaging on the page. This tactic, to an extent, does create broader opportunities for readers to assume a role as critical rather than passive readers. But there exists a risk that relieving readers of the burdens and anxieties of the disaster of the fictional world also undermines each text's covert pedagogical agenda, which is to galvanise a generation of what Geraldine Massey and Clare Bradford term 'ecocitizens' (2011, p. 109).

At the time of each novel's publication (in 2008 and 2009 respectively) these texts offered a small window of time before their designated point of no return, thus creating a sense of immediacy in order to bolster the impact of their environmental warnings to readers. Now, as even the 2017 volume loses its status as an alarming and imminent prophecy, it becomes necessary to re-examine these texts in regards to the other methods by which they continue to contribute to the socialisation of young readers. The use of comedy and humour in these texts demonstrates one such technique that endures even as the texts themselves age.

\section{'Dead ashamed': positioned to laugh, encouraged to change in The Carbon Diaries 2015}

The Carbon Diaries 2015 marks its difference from other young adult environmental dystopias through the representation of incongruities of certain comic and tragic aspects of worldwide environmental degradation. One of the primary functions of environmental texts for young readers is 'to socialize young people into becoming the responsible and 
empathetic adults of tomorrow by positioning readers as ecocitizens, dedicated to both sustainable development in the local sphere and also to global responsibility' (Massey \& Bradford 2011, p. 109). In line with this, The Carbon Diaries 2015 performs a pedagogical function, attempting to comment on and socialise young readers into the environmental behaviours prescribed by the implied author of the text. The use of humour in the novel can be read as part of the text's agenda for promoting specific environmentally-responsible behaviours. Although there is much in both texts which is decidedly unfunny-such as Laura's older sister's almost-fatal illness in 2015 and the terrorist bombings in 2017-both texts utilise comedy and humour as methods to position readers to consider and respond to the importance of environmental responsibility, at both personal and global levels.

As Bergson (2009, online) writes, 'In laughter we always find an unavowed intention to humiliate, and consequently to correct our neighbour, if not in his [sic] will, at least in his deed'. In The Carbon Diaries 2015 the humiliations visited upon Laura and her family often cause them to correct their behaviours and in doing so they serve a parable-like function for readers-thus the text attempts to encourage the reader to correct their own behaviour in accordance with the overt ideologies of the narrative. This corrective humour is particularly apparent in conjunction with the representations of adult-child dynamics in the text. The infantilisation of many of the adult figures and corresponding reversals in adult and child roles in the text become key to illustrating to young readers what perspectives and behaviours are deemed appropriate or inappropriate in the contemporary struggle against further environmental degradation. The text employs an intense critique of the carbondependent habits and routines of adults through Laura's wry narration of the ironies of her parents' failings.

Most of the humour centred on adults in the texts is unkind: it mainly presents them as incompetent and passes clear judgement condeming those who cannot conform to a new set of regimes. This is especially the case with Laura's parents, Nick and Julia. When Julia Brown is required to forgo the use of her car in favour of environmentally-friendly bus travel, for example, she is incapable of adjusting. With 'eyes filled up with tears' Julia 
'stroke[s] the bonnet of her car', whispering 'It's not forever' (2008, p. 12). Her relationship with her car becomes a parody of the type of intense bond a reader may expect would be reserved for relationships with sentient beings such as other humans, or pets. The saga continues with Laura recounting in her diary how Julia's ineptitute caused them to miss two buses in a row: first because Julia could not run in her impractical high heels and second because Julia could not locate her all-important carbon card in the lining of her bag (p. 11). Days after this episode, and only a week into carbon rationing, Laura's narration juxtaposes another comic reference to Julia's bus antics-'My family has disappeared. Dad spends all night in his study on his laptop, Mum is always lost on a bus somewhere' -with her own decidedly less amusing admission of being plagued with nightmares (p. 15). While Julia continues to display incompetence and an attachment to the lifestyle that contributed to the environmental degredation, Laura evidences a much more serious response to the changes. Laura recognises the dire circumstances they are in and models an awareness and maturity that exceeds that of Julia to the point where, by the end of the year, Laura is the only one of the family to make it through without exceeding her carbon limit. Through this contrast the text identifies the young as being those with the most potential to display the necessary flexibility and responsibility to embrace new regimes and, at the same time, subtly cautions young readers not to become-like Julia-fodder for mockery. Frequently functioning as 'judgement of life' (Colebrook 2003, p. 149) and 'the adoption of a point of view 'above' a context, allowing us to view the context from 'on high' (p. 153), the ironic mode reinscribes rather than destabilises rigid subject positions (p. 138). In The Carbon Diaries 2015 the irony of a sixteen-year-old girl understanding and responding to the environmental crisis with greater maturity than her mother creates space for a questioning of whether alternately helpless and hopeless adults can be trusted to competently enact the change required to prevent the catastrophic outcomes of carbon overuse. It becomes the role of young person to be critical of, and in turn choose to reject, adult behaviours from a position 'above'. This role taps into the notion of young person as saviour, a concept which, as Margot Hillel explains, has a long history $(2003$, p. 57). 
This reversal of the 'traditional' view of the adult as self-regulating, wise and morally mature (Sambell 2004, pp. 256-7) at first appears to grant Laura and other young people in Lloyd's texts greater agency and authority over their own lives. As Laura indicates, her father has 'never acted out like this before' (2008, p. 102), yet in the face of carbon restrictions both of her parents devolve into caricatures of the mid-life-crisis-driven adult desperate to relive youth. Over the course of the novel both Julia and Nick disappear briefly or run away for a time, leaving Laura and Kim to care for themselves. Both parents also turn to mind-altering substances: Julia pours 'half a bottle of wine down her throat' (p. 8) while Nick keeps a stash of alcohol (p. 95) and comes home drunk after losing his job (p. 87). Julia and Nick also tend to look to others, especially their children, to solve their problems, while their own child-like behaviour places their children in a position where they must assume the parental role. When Nick has been drunk for five days in succession and Julia goes into denial, for example, it is Laura who does the simple kindly act of taking her father a cup of coffee (pp. 102-3). The depiction of Nick and Julia's deterioration in the early stages of carbon rationing is narrated as simultaneously comic and tragic. After Nick trades in Julia's car for items that will help the family to live a more sustainable lifestyle (including livestock and tools), Julia abruptly packs and leaves the family. The scene where Laura witnesses her mother's preparations to leave, followed immediately by the sight of her father's struggle to wrangle the pig that he has just acquired, presents both characters as simultaneously comic and tragic:

[Julia] hurled a Prada loafer into the bag.

'I'm your goddamn mother, Laura, but if I don't take a break from...' she waved an arm towards the back garden, echoing with pig squeals, '...l'll go mad, plain mad.' [...] She took my hands in hers. 'Honey, I know what I am. I'm a difficult, neurotic, silly, woman who bangs on about the past [...] I drive my husband and my daughters crazy and I can't make a soufflé or sew a button to save my life. But I do love you and I am trying. But right now, it's not good enough, for any of you, or for me either. I've got to get away. Now. D'you understand?'

I had never heard Mum make sense like this. I just nodded. [...] 
'Laura!' Dad's voice, panicky. 'Where are you?'

I dragged myself off the bed, opened the bedroom window and looked down into the back garden. He was covered in dirt, battling the pig in a headlock. I bit back a laugh. (pp. 183-4).

It is through the blending of these two modes that the text attempts to persuade readers to contemplate what kind of productive and proactive changes might be required to avoid outcomes like those modelled by Julia and Nick throughout much of the novel.

At the same time, in affording young readers the vision of young people capable of assuming adult responsibility-and suggesting they will even be better adults than their predecessors - the text subtly offers advice to implied readers as well. The text identifies traits and behaviours, such as drinking and running away, which are often viewed as being particularly adolescent and uses them as part of a negative critique of the adults in the novel. Using humour to ridicule these traits demonstrates the way the text seeks to critique those same traits/behaviours in the young adult audience. Alice Curry argues that:

[i]n post-disaster novels for young adults, tension can be perceived between the common construction of subjectivity as a stable, autonomous category and an acknowledgement that the visibly decaying landscape must nevertheless impact upon the identity formation of its inhabitants. (2013, pp. 46-7)

Thus, to become an adult in the evolving environmentally aware world you must leave behind 'everything [you] like' (Lloyd 2008, p. 215). As much as the text is focused on a critique of irresponsible adult behaviour, it also highlights the transformations of those young adults who must accept a new world of self-regulation and maturity.

Roberta Seelinger Trites, in considering the role of humour in adolescent novels about school, argues that; 'antiestablishment humor helps teenagers reconcile themselves to living with the establishment' $(2000$, p. 35). Such a viewpoint indicates the potentially paradoxical 
role of humour in considering matters of power and agency in young adult texts, as humour-often considered a tool of resistance and subversion-can also contribute to reinscribing a status quo that disempowers the young. The application of humour in The Carbon Diaries 2015 functions similarly, simultaneously encouraging agency and also limiting it by restricting alternate subject positions for young adults in the narrative.

The illusion of adults being in control is particularly obvious in the figure of Bob Jenkins, Laura's school principal. During an assembly speech filled with flowery rhetoric, in which he expresses his pride in the students and speaks of 'what an immense privilege for him it was to work with such a fantastic group of young people' (2008, p. 269), Jenkins tells the school that there will be no heating or hot water until the spring term. There is an evident gap between the conventional headmaster rhetoric and the reality that the college has overspent its rations, one which indicates that in effect Jenkins is powerless. His statement that Laura's 'generation would be thanked by all those to come', as they 'made the choice to change' and 'save the planet' (p. 269), is an acknowledgement of his own self-centeredness, as well as that of other members of his generation. Inwardly, Laura counters Jenkins with sarcasm: 'Er, excuse me, what choice? I ain't old enough to vote' (p. 269). It is, of course, a false binary-Laura and Jenkins both are capable of creating change even at their respective ages, yet this ridicule highlights the shift of blame for future degredation onto the young adult, reinforced by Laura's subsequent statements. Her feeling of being 'dead ashamed' for desiring a return to her former consumerist lifestyle, coupled with the deadpan exaggeration that she is going 'dead right wing' (p. 269), mean that the layers of humour used to supposedly undermine Jenkins' statement create an impression that taking on responsibility for rectifying the environmental situation is the only acceptable course of action if young people, like the implied reader, want to avoid the shame Laura feels. Semantically, the repetition of the term 'dead' in both statements also implies a negative (even dire) outcome.

Jenkins' naïve and useless attempts at authority are also parodied in an interaction with one of the school's teachers, Gwen Parry-Jones. When he announces to the assembly that 'the ladies amongst your tutors have prepared you some cookies and snacks', Gwen responds by 
saying 'You're not going to use rationing as an excuse to eradicate eighty years of female emancipation' (p. 269). Bob and Gwen are both depicted as operating within stereotyped viewpoints: Bob as assuming that any cooking must be done by women, and Gwen by taking any sexist comment as a slight upon the entire feminist movement. This parody makes them figures of fun, and therefore not to be taken seriously. Similarly, when she comes to see Laura's parents about Laura's poor performance at school and Laura's father suggests that 'Education isn't everything', Gwen responds:

'I presume you are trying to be amusing, but it has taken womenkind several millennia to escape the constraints of a patriarchal society operated by men, dominating women and oppressing them. Education is freedom.' (pp. 135-6)

Even if Laura's father is making excuses for an ill-considered comment, Gwen's reaction is presented as overly dramatic, especially in its use of the stereotypical (and tautological) phrase: 'patriarchal society operated by men'. In his explanation of parody, Chambers notes that 'If the chosen material is a preexisting model, the parodist is likely to have selected a work with a style and/or subject matter larded with quirks and/or oddities' (2010, p. 13). Certainly, the novel draws upon feminist discourse that speaks of a binary opposition of male dominance and female repression to set Gwen up as an extreme, and initially twodimensional, character. Her stereotypically militant feminist way of talking, as demonstrated above, suggests an identity that is not self-reflective, one that makes sound without background thought; one which responds as it has been programmed.

Nonetheless, Gwen is the most complex of the adult characters. Despite initially being parodied as a stereotypical militant feminist who spouts cliches, unlike the incompetent Bob Jenkins, she cannot be dismissed. When the village is inundated with flood, not only does Gwen save a drowning woman (as well as Laura herself, by implication) (2008, p. 341), but Gwen also motivates the village to solve their own issues about returning home after the flood, rather than waiting for the authorities (p. 368). As Laura says, 'She is some kind of hero' (369). The genre demands of young adult fiction mean, however, that she cannot 
remain the kind of hero that she is at the end of The Carbon Diaries 2015, as the young people must take the lead. The means by which Gwen is ultimately disempowered are discussed in the 2017 section below.

The 2015 text often uses the ironic disempowerment of adults to openly advocate for the young to take a more active role in response to environmental degradation. Yet the use of comic modes of criticism are not exclusive to the representation of adult characters, as comedy also features in how the text uses young characters as exemplars of the seeming necessity of behavioural reform. Laura's narration in her diary entries at times pass judgement on her peers by juxtaposing their words with their behaviours. For example, Laura describes the contrary attitudes and actions of her fellow band member, Claire:

Claire got heavily into hardcore Straight Edge. She was so militant. You couldn't even unwrap a Snickers around her without a lecture on skinny cocoa-bean farmers. Anyway, she blew it by getting back with her snotty boyfriend and eating a bacon sandwich-all on the same day (p. 7).

While Laura is a character who tends not to veer towards the extremes displayed by others, her position of superiority in contrast to Claire is undercut by the veiled presence of the adult author. Laura may be a leading figure who judges from above, but she is also one who is judged from (further) above, in that the narrative similarly employs comedy in describing Laura's mis-steps as part of an agenda encouraging behavioural reform. Laura's comic selfjudgment tends to be less critical than her judgment of others. Instances where she does make fun of her own behaviour often tend towards slapstick, such as when she recounts her efforts to ride an old bicycle in the snow. At the same time, the instances where Laura judges her own behaviour also covertly set up associations that signal what the text deems to be shameful or selfish in the face of ecological disaster.

Irony, according to Claire Colebrook (2003, p. 1), rests in contrarism. This form of expression relies on a 'doubleness of meaning, where what is said is limited or undercut by what is 
implied' (Colebrook, p. 14). The core of The Carbon Diaries 2015's blend of humour and tragedy rests in such a doubleness of meaning. During the summertime when the city is suffering through high temperatures, Laura repeatedly sneaks into the kitchen and opens the fridge solely to 'cool down'. Her diary entry regarding this illicit behaviour ends with the humorous admission: 'Man, I'd kill to sleep in there, next to the cottage cheese' (2008, p. 210). The narrative then immediately reverses this levity in the next entry, which sees 'colossal forest fires all over France' that cannot be put out because of water shortages ( $p$. 210). A similar technique is used earlier in the novel when Laura admits she 'sneak[s]' into her father's office in order to use the internet; in the next diary entry, the mood changes and Laura tells how there has almost been a riot because someone has batteries available thatillegally-do not require a carbon swipe (pp. 46-7). In other words, Laura can mock herself for behaving against the rules, but similar illegal actions at wider level create havoc. Laura's minor transgressions may not be punished in the moment, but the juxtaposition of Laura engaging in a problematic behaviour on an individual level with exaggerated global repercussions sets up a system of reward and punishment veiled in humour.

Laura states at the beginning of the novel that '[i]t's all kind of a choice' (p. 6). Yet the repetition of individual reward correlated with global punishment (i.e. Laura cools herself for a few moments; fires devastate a country) converges with the didacticism of the text to shape a landscape where certain 'choices', as determined by the text, are encouraged, while other choices are discouraged. Where the humour of the text facilitates this didacticism through obscuring it, the relief of tension or anxiety that humour can facilitate also creates a particular dilemma in terms of the text's socialising agenda. The narrative exists at a nexus of tragedy and humour that becomes implicated in attempts to both incite and relieve the anxieties of the reader. Moments of comedy are not uncommon in dystopian literature as a genre, even in texts which are predominantly serious in mode. (Phillip Reeve's 'carnivalesque' [Sambell 2004, p. 257] Predator Cities novels operate differently. See Sambell 2004 for a longer discussion on the first of these novels.) The outrageous Effie Trinkett in The Hunger Games (2008) for example, with her off-centre pink wig, self-serving nature and disingenuous bubbly patter serves both to reinforce how far the authorities are removed 
from the life of Katniss and her family, and to provide a small measure of comic relief in the tension of waiting for the results of the ballot to see who the tributes for the Hunger Games will be (Collins 2008 pp. 23-4). In other texts, the way in which language from twentieth or twenty-first century life has decayed can serve both to provide moments of comic relief, and to underscore how much the world of the implied reader has been lost. For example, in Laurence James' The Horned God, set in a quasi-medieval world after nuclear disaster, a sign for double glazing now reads DO LEG IN (1992, p. 66). In both The Carbon Diaries texts, the relationship between humour and tragedy both unsettles the implied reader and provides a measure of relief through the catharsis of humour. The Carbon Diaries 2015 concludes with Laura's diary entry on December $31^{\text {st }}$ where she recounts a near farcical final confrontation with Tracey Leader, who had been terrorising Laura's neighbourhood and shirking her environmental responsibilities throughout the year:

And then Mousy Woman-of all people-stepped forward. [...] Mousy shoved past Tracey, lifted her arm high and smashed her hammer on the boot of the Jeep. Tracey went to drag her away, but suddenly Loud Dad was there. He pushed Tracey to the ground and dragged his chainsaw across the Jeep door, spraying sparks everywhere. And then a crossbow dart thudded into the front tyre. In 30 seconds the Jeep was covered in crazed neighbours, jumping all over it like a gang of jackals [...]

Mousy Woman turned to Tracey. 'Tracey Leader,' she gasped. 'The law might not be able to touch you, but we can. Now clean up or piss off!'

It was about the best thing I've seen all year. (2008, pp. 377-9)

The caricature-like descriptions of the adults who stood up to Tracey ('Mousy Woman', 'Loud Dad') alongside the imagery of chainsaws and arrows being used to disable a Jeep make for a rather cartoonish end to the dramatic life-or-death struggles that Laura recounted in the previous pages of her diary. This scene relieves some of the anxieties that have been building in the narrative through Laura's tales of rising flood waters, her family's separation and desperation to find each other and the near deaths of Laura's sister, Kim, and 
neighbour Arthur. It is an unusual return to the (quasi) status quo. Humour has returned to Laura's narration and her neighbours have reverted to ridiculous behaviours. Now, though, these behaviours are much more in line with an agenda for ecological preservation: they attack Tracey Leader and her Jeep, representatives of the selfish behaviours adults like Nick and Julia evidenced during the early days of the rationing scheme. The humour of this scene once again evidences the text's stance on the necessity of adopting particular traits and behaviours and rejecting of others.

\section{'No guns, no bombs, no escape': catharsis and control in The Carbon Diaries 2017}

Humour as a strategy in The Carbon Diaries 2017 is used both self-consciously and ironically by a number of characters in helping them to gain control over their environment, and as a cathartic device to battle the depression provoked by the systemic changes-and blundersthey have endured. While this mirrors the uses of humour established in 2015, the sequel takes on a more urgent, darker tone, and thus the emphasis on humour as a mode of catharsis becomes all the more important. This is especially signficant in the narrative since carbon rationing, as well as protests against an increasingly chaotic government rule, emerge in heated and divisive politics. In this context, the narrative's focus on humour as release makes clear a society grappling with both the tedium of the environmental crisis, and also the tensions and anxieties it has provoked. On her return to university, for example, Laura is assigned a project to 'design a direct action campaign to change how and why people drive cars', which she describes as 'yawn to the power of $n$ squared' (p. 39). Yet Laura is able to invert the seriousness of the project to create 'a joke anti-car kit' (p. 47), which includes a 'joke tyre slasher knife' (p. 59) and a 'Fake Car Scratch' (p. 69) as well as '3 dummies and a range of wigs, taches and glasses to dress 'em up' in order to avoid being fined for having less than three people in a vehicle (p. 64). The gag is a coping mechanism, a release of the tension described in Critchley's formulation of humour that also enables some feeling of control. In this way, as in 2015, Laura finds ways to ease the repressive nature of a new eco-conscious culture as well as a means to mock the lives they now lead. As Critchley writes, '[h]umour both reveals the situation, and indicates how the situation might be changed' (2002, p. 16). This is not unlike Nick's disastrous plan to convert pig manure to fuel 
and his 'vintage homemade carrot wine', which 'taste[s] like what villains slip into goblets to poison people in Shakespeare' $(2008$, p. 8). While the humour here is much less selfconscious than Laura's joke anti-car kit, this does point to the use of humour as a means of managing adversity and as a way to formulate new kinds of behavioural paradigms that filter into the public consciousness. The desperate environmental situation might not be changed via flawed attempts at pig fuel and carrot wine; however, Nick's efforts towards environmental sustainability do highlight how transformation is required at both micro- and macro-levels. That is, change cannot occur at either the level of government or the individual alone. In this way, humour is as much a mask for the tensions caused by the enormity of the change required, as it is a means through which to expose the realities being addressed.

Humour is also emphasised as being something that can help people retain a sense of humanity, most often in the form of black humour. As Patrick O'Neil highlights, black humour can be understood as a 'defense against the horror' (1983, p. 151), a means of processing that which is 'threatening' in order to 'laugh again instead of despair' (p. 165). Drawing on Freud, O'Neill contends that black humour, like all humour, is a protective 'mechanism against the deficiencies of life [...] a rechannelling by the superego of feelings of guilt, anxiety, fear, or terror into pleasure-producing form, analogous to dream-work or indeed art-work' (pp. 150-1). During Laura's experience in France and Italy, she and her friends are often under extreme duress-struggling without food or finances, for example, and eventually detained in a prison-camp-yet it is here that their survival is predicated on their ability to be distanced from events by reflecting upon them in a sardonic way. Black humour as a narrative tool here is a vehicle through which readers can process moments that are profoundly distressing.

While imprisoned in a Sicilian detainment camp, for example, Laura notes how Claire, a friend who has also been captured, demands to be able to make contact with their families: 'The officer nodded, but mimed there were no working fones and then another stopped her and offered to sell her a fone card' (2008, p. 289). The scene is, as O'Neill describes, 'a joke 
without humour' (p. 146) that enables the horror of their situation and experiences to be managed without collapse into the 'facelessness of the void' (1983, p. 165). Similarly, when Laura describes the officers in the camp, she explains how 'one really brutal squad of bitches [. . .] made us clean toilets with bits of old rag and broken brushes. Again laughing, videoing, taking fotos. What for I don't know, they could hardly show 'em on flickr' (2008, p. 289). This is, as O'Neil notes, a 'form of humour which, using [...] bitterness, and sometimes despair, underlines the absurdity of the world' (1983, p. 146), but also its brutality.

The bitterness and despair of the Carbon Diaries world are also apparent in the character of Gwen Parry-Jones, Laura's former teacher who resurfaces in 2017. In this second text Gwen is central to providing alternative living arrangements for Laura (2009, p. 24). She also provides important information about the political stresses of the international water situation (p. 233), and rescues Laura and her friends from needing to hitchhike their way to Sicily (p. 224). Nonetheless, Gwen is ultimately disempowered in the novel's terms by her decision to join the militant $\mathbf{2}$ group. She says to Laura:

Once you asked me about my family, my life, who I am. Well, I'll tell you. I'm done with it all. All I care about is putting an end to this disgusting, messed-up, futile, hypocritical system that is screwing the planet. And right now that only means one thing. (italics in original, p. 268)

For Gwen, it is about extremes, which the novel suggests is not the ultimate answer. Despite all the good that she has done, Gwen disappears into a kind of radicalism that the text suggests will not solve the problems of international conflict over managing limited resources. The final image of Gwen is a message she sends to Laura showing a picture of the chaos in Milan caused by the bomb set off by $\mathbf{2}$, with the message: 'don't like goodbyes ... Milan then who knows? It feels like the only sane place to be. Take care GPJ' (p. 274). However, Laura's previous diary entry has aligned the reader away from agreeing with the actions of $\mathbf{2}$, and by extension also away from Gwen's view that $\mathbf{2}$ is providing 'the only sane place to be'. Laura's previous entry reads: 'The shit's really hit the fan in Milan. The $\mathbf{2}$ 
bombed and destroyed a hotel [. . .] and the city is in total chaos and lockdown' (p. 273). Through this diary entry, the image Gwen has sent showing the chaos in Milan (p. 274) the text seeks to encourage rejection of Gwen's views. Gwen arrives in the narrative via a portrayal of her as a vehicle for humorous extremism-as a stereotype of a militant feminist-but she departs in a deadly form of terrorism. Her function in the texts is to allow the young adult protagonists 'to test their own social power and go on in life to be somebody. [...] Youth itself becomes the real hero' (Burnaford 2001, p. 175) and therefore she cannot stay as a significant figure in Laura's life. The fact that Gwen is no longer presented as funny puts her at odds with the mode of the novel: she is a figure of tragedy rather than comedy and thus in the terms of the text it is appropriate that she takes no further part in the narrative.

\section{Towards hope?: seeking a future blueprint}

Towards the end of The Carbon Diaries 2017, the novel suggests the possibility of hope once more, as Laura is motivated by her experiences to create a world that works towards a revolutionary form of sustainability. As the novel moves away from the violence and horror of the European camps and the London riots, shifts in ideas about the self emerge, along with a general sense of cultural change including challenging stereotypically gendered narratives of the body: 'Women have all got arms like tree trunks now ... All of that Size 0 shit has totally vanished' (2009, p. 308, ellipsis in the original). Physical spaces are also transformed, as London is overrun:

with pigs and chickens grunting and clucking all over the place. All the houses and buildings have those orange plastic water catchers on them and every single bit of garden and scrap land has veg growing in it. Even the roofs of bus shelters are either grassed up or turned into solar catchers (p. 321).

This image of modern London, currently a haven of concrete and pollution, is seductive, and suggests that real change is being proactively pursued. 
However, while these representations of city as farming space may appear romantic in their suggestion of a pre-industrial economy, the darkness behind the text still remains, as the guerilla activities of the radical group 2-so named because it is thought that if the earth warms up two degrees the ecological problems will be devastating (p. 71)-bring an impending sense of war. Indeed, while numerous moments imply hope, the text continues to assert a political and proactive agenda targeted at government forces who fail to respond adequately to the needs of its people, resulting in a series of non-violent guerilla tactics. As an expression of protest, for example, Laura and her friends create some 'genuine [. . .] guerilla art' (p. 332) to provoke the city mayor. Using a data projector and some computer generated imagery, they direct a 'beam of light [. . . ] on to City Hall, transforming it instantly. Super dramatic' so that 'every single window' now appears to have been 'smashed to pieces' (p. 335). The humour here is black, a play upon violence in an act that is ultimately harmless, yet charged with the symbolism of resistance and defiance, 'disruptive of accepted values and systems' (O'Neill 1983, p. 149). Linking back to the anti-car kit project, 2017 highlights how humour and creativity can be used to act against oppressive regimes, and to agitate for transformation to occur.

This paper has highlighted how Lloyd's The Carbon Diaries novels use humour, comedy, irony, and parody as part of their attempts to position readers towards developing an understanding of the ecological crises that face the contemporary world, and the challenges that exist at the personal local, national and global levels about how best to respond to the threat of ecological devastation. Ultimately, however, the reader is left with what Laura does not want-and no blueprint for the future. In 2017, she decides against radical politics and, despite specifying that she wants a future with 'no guns, no bombs, no escape' (2009, p. 400), how Laura will manage this is never made clear. In one sense, the ending of the Carbon Diaries saga could be read as opting out. The text cannot commit to concrete solutions to the complex problem of climate change other than making the suggestion that a global reduction of carbon consumption and the improvement of interpersonal communications is necessary because, as Von Mossner $(2013$, p. 78$)$ writes, 'the nature of the problem precludes a neat and happy ending'. But the uncertainty that still exists at the end of 2017 
can also be read as a method intended to place the responsibility back upon the reader. Just as Laura understands that she must find her 'own way' of dealing with the political situation (2009 p. 397), the ending can be understood as positioning readers to consider what their path might be in relation to the problems of climate change. As such, Lloyd's texts demonstrate that the process of trying to work out how best to use the natural environment ethically and sustainably will meet with 'failure and error', but that it is important to continue to ask such questions and to 'act, with due care, in the very face of that recognition' of error and failure (Szerszynski 2007, p. 351). In other words, there may be no answer to the questions of how to reduce the likelihood of ecological disaster, and how best to bring about responsible use of the environment, but it is important that these questions continue to be asked.

\section{References}

Bergson, H., (2009) Laughter: An Essay on the Meaning of the Comic, trans. C. Brereton and F. Rothwell.http://www.gutenberg.org/files/4352/4352-h/4352-h.htm Accessed 18 June, 2013.

Burnaford, Gail E. (2001) 'And the Oscar goes to...Teachers as Supporting Actors in Fiction for Young Adults.' In P. B. Joseph and G. E Burnaford (eds) Images of Schoolteachers in America, New Jersey: Lawrence Earlbaum, 173-83.

Chambers, Robert (2010) Parody: The Art that Plays with Art, Studies in Literary Criticism \& Theory 21. New York: Peter Lang.

Chase-Dunn Christopher \& Lawrence, Kirk S. (2011) 'The Next Three Futures, Part One: Looming Crises of Global Inequality, Ecological Degradation, and a Failed System of Global Governance'. Global Society 25 (2): 137-53.

Colebrook, Claire (2003) Irony. New York: Routledge.

Collins, Suzanne (2008). The Hunger Games. London: Scholastic. 
Papers 25.1 (2017)

Conference Series LLC (2013-2017) 3rd World Congress on Climate Change and Global Warming. http://climatechange.conferenceseries.com/asiapacific/events-list/disaster-riskreduction-drr Accessed 17 February 2017.

Congreve, William (1997 [1698]) 'Amendments of Mr. Collier's False and Imperfect Citations.' In S. McMillin (ed.) Restoration and Eighteenth-Century Comedy. New York; London: Norton, pp. 513-6.

Critchley, Simon (2002) On Humour, Thinking in Action. New York: Routledge.

Curry, Alice (2013) Environmental Crisis in Young Adult Fiction: A Poetics of Earth.

Basingstoke: Palgrave Macmillan.

D’Arcens, Louise (2014) Comic Medievalism: Laughing at the Middle Ages. Cambridge D.S.: Brewer.

Hillel, Margot (2003) “"A Little Child Shall Lead Them”: The Child as Redeemer'. In R. McGillis (ed) Children's Literature and the Fin-de-Siecle. New York: Greenwood Press, pp. 57-67. James, Lawrence (1992) The Horned God. London: Bantam Lloyd, Saci (2008) The Carbon Diaries 2015. London: Hodder Children's. Lloyd, Saci (2009) The Carbon Diaries 2017. London: Hodder Children's. Lyytimäki, Jar (2015) 'Rare Exports: Irony about Northern Nature and Commercialized Culture'. Nature and Culture 10 (2): 178-98.

Massey, Geraldine and Bradford, Clare (2011) 'Children as Ecocitizens: Ecocriticism and environmental texts.' In K. Mallan and C. Bradford (eds.) Contemporary Children's Literature and Film. New York: Palgrave Macmillan, pp. 109-26.

Mills, Brett (2005) Television Sitcom. London: British Film Institute. 
O'Neill, Patrick (1983) 'The Comedy of Entropy: The Contexts of Black Humour', Canadian Review of Comparative Literature 10 (2): 145-66.

Sambell, Kay (2004) 'Carnivalizing the Future: A New Approach to Theorizing Childhood and Adulthood in Science Fiction for Young Readers'. The Lion and the Unicorn, 28: 247-267.

Sutton, Dana (1994) The Catharsis of Comedy. Lanham and London: Rowman \& Littlefield.

Szerszynski, Bronislaw (2007) 'The Post-Ecologist Condition: Irony as Symptom and Cure'. Environmental Politics 16 (2): 337-55.

Trites, Roberta Seelinger (2000) Disturbing the Universe: Power and Repression in Adolescent Literature. lowa City: University of lowa Press.

United Nations (2016) Global Issues: Environment.

http://www.un.org/en/globalissues/environment/ Accessed 10 October, 2016.

Von Mossner, Alexa W. (2013) 'Hope in Dark Times: Climate Change and the World Risk Society in Saci Lloyd's The Carbon Diaries 2015 and 2017.' In B. Basu, K. R. Broad, and C. Hintz (eds.) Contemporary Dystopian Fiction for Young Adults: Brave New Teenagers. New York: Routledge, pp. 69-83.

\section{Biographical Notes}

Dr. Alyson Miller is an award-winning writer, critic and scholar, with expertise in scandalous literature, and the representation of freaks in literary and popular texts. She currently teaches literary studies and professional and creative writing at Deakin University, Australia. A 2015-17 Victorian Arts Council grant is funding her most current project, a graphic novel/prose poem collection examining a post-atomic Alice's Adventures in Wonderland (with Cassandra Atherton and artist Phil Day).

Dr. Rebecca Hutton teaches children's and young adult literature at Deakin University, Australia. In addition to previously published papers on YA dystopian texts (with co-authors Elizabeth Braithwaite and Alyson Miller), her recent publications also include co-authored chapters in Routledge Companion to Fairy-Tale Cultures and Media (2017, with Emma Whatman), The Middle Ages in Popular Culture: Medievalism, Genre and Identity (2015, with Clare Bradford), and an article published in Papers on music in young adult LGBTQ fiction. 
Dr. Elizabeth Braithwaite has long had research interests in fiction for young adults which focuses on global disaster. She has had a number of publications in Papers: Explorations into Children's Literature, and has also had research published in Barnboken - Journal of Children's Literature Research, Bookbird: A Journal of International Children's Literature, and interjuli. She is an administrative officer in the School of Humanities and Social Sciences at Deakin University, Australia, and is also a keen amateur musician and composer. 